\title{
A GIS SPATIAL ANALYSIS MODEL FOR LANDSLIDE HAZARD MAPPING APPLICATION IN ALPINE AREA
}

\author{
C. AUDISIO ${ }^{1}$, G. NIGRELLI ${ }^{2}$, A. PASCULLI ${ }^{3}$, N. SCIARRA $^{3} \&$ L. TURCONI ${ }^{2}$ \\ ${ }^{1} \mathrm{PhD}$ at University of Chieti-Pescara, Department of Engineering and Geology, Via dei Vestini, Chieti (Italy). \\ ${ }^{2}$ CNR IRPI Torino, Strada delle Cacce 73, Torino (Italy). \\ ${ }^{3}$ University of Chieti-Pescara, Department of Engineering and Geology, Via dei Vestini, Chieti (Italy).
}

\begin{abstract}
This research describes an application of an existing method for evaluating landslide susceptibility in alpine contest that may be considered a useful support in better land-use planning and risk management. In order to perform the method and improve it creating landslide maps of probability, we investigated the several conditioning factors that in general affected these morphological processes. Firstly, a landslide inventory was prepared using both in-depth analysis of historical records and aero-photos (or orthophotos) investigation. Secondarily, a set of conditioning factors which may affect slope movement and failure (particularly lithology, geomorphology, land use, slope angle and aspect) was considered. Then, the method involved the application of GIS techniques, specifically, spatial Data Analysis application. The thematic maps of conditioning factors overlapping together with the support of the raster calculator allowed the susceptibility map creation. The method was applied to the Germanasca Valley, a small basin in the Italian Western Alps. This easy to use method allows one to individuate various classes of susceptibility and to identify slope, lithology and geomorphology, driven by old landslide events as the main conditioning factors. Furthermore, the individuation of area susceptible to landslides verification is strictly related to risk and, as a consequence, this method permits specific zone to be selected for detailed engineering geology studies in land-use planning.
\end{abstract}

Keywords: GIS, landslides, susceptibility zonation, western alps, Italy.

\section{INTRODUCTION}

A landslide can be defined as the movement of a mass of rock, debris or earth down a slope [1]. Landslides can have several causes, including geological, morphological, physical and human, but only one trigger. The most common natural landslide triggers include intense rainfall, rapid snowmelt, water-level change, volcanic eruption and earthquake shaking [1]. Also other kinds of phenomena like pyroclastic grain crushing, due to suction variation, may induce landslides in a volcanic area [2]. In addition, landslides represent one of the primary and serious risk factors in mountainous areas where the human impact is high, so potential landslide-prone sites should therefore be identified and monitored. The definition of a landslide risk map includes zonation showing temporal probability (likelihood) of a landslide occurring throughout an area [3]. On the contrary, the basic concept for landslide susceptibility involves the spatial distribution of landslides-prone areas without any temporal implication [4]. Tools for handling and analyzing spatial data (i.e. GIS) may facilitate the application of quantitative techniques in landslide hazard assessment and mapping [5]. The increasing use of GIS techniques since the 1980s has led to the development of methods that could address these problems [6-8]. This paper intends to deal with these problems and illustrates a method that, incorporating GIS (the software is ESRI ArcGIS ${ }^{\circledR}$ ) techniques, is also easily applicable 
to small mountain basins. A multi-criteria evolution technique, characterized by advantages like the requirement of just few parameters and fast analysis, was selected. This method was verified on a small area in North-Western Italy: the Germanasca Valley. The resulting cartography can work at small-scale $(1: 50,000-1: 100,000)$ on small or medium basins, so the result may be acceptable even when various types of landslides are considered together. In addition, the subdivision need not be necessarily detailed but reliable. The map can be used not as a predictive tool, but rather to individuate a spatial prediction of landslide occurrences, so that a monitoring system started there.

This can be a further valid support for local authorities, need to acquire, quickly, data and reliable technical support.

\section{THE STUDY AREA}

The Germanasca Valley lies in the central sector of the Cotian Alps (Western Piedmont, NW Italy), bordering to the North, West and East with the Chisone Valley and to the South with the Pellice Valley (Fig. 1). It extends around $197 \mathrm{~km}^{2}$ in area. The hydrographic network has a convergent dendriform pattern. The main morphometric features are listed in Table 1. The geological properties of the study area and the chief morphogenetic processes associated are described in the next sections. Human intervention is widespread in the valley bottoms and in the mid-lower slope areas, where villages are located and the chief agro-silvo-pastoral activities are carried out. Talcum mines and quarries are also present. In the Germanasca Valley, the pluviometric regime is Prealpine continental [9].

The mean monthly rainfall has a bimodal pattern with two maxima, a higher one in spring and a lower one in autumn, and two minima, one in winter and the other in summer. Spring is the season with the greatest amount of rainfall and number of rainy days, while autumn is marked by maximum rainfall intensity. The seasonal rainfall distribution is similar throughout the basin. The average monthly temperature in Perrero station ranges from $-0.1^{\circ} \mathrm{C}$ in January

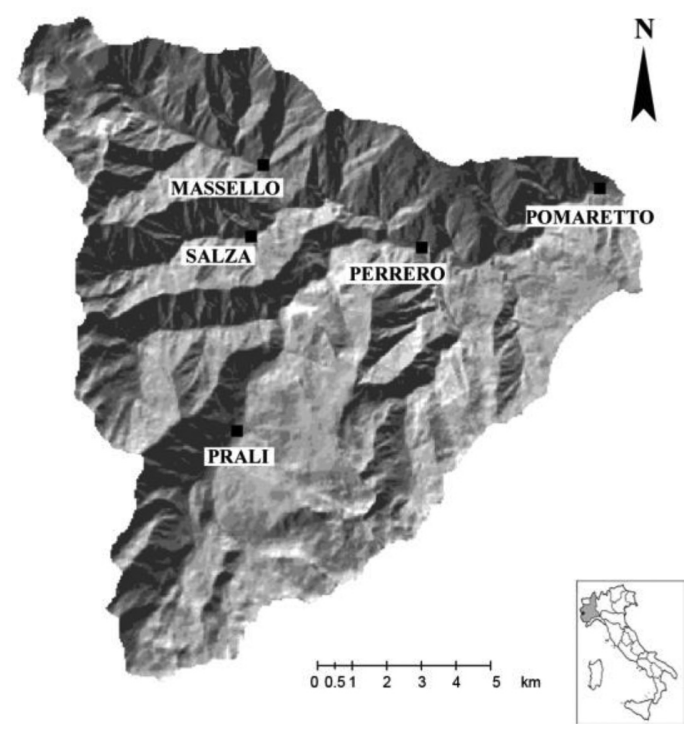

Figure 1: Sketch map of the Germanasca Valley (Piedmont Region, NW Italy). TIN figure on the DEM $50 \times 50$ grid. The squares indicate the main villages of the valley. 
Table 1: The chief morphometric parameters of the germanasca valley. measurements taken with gis techniques on the regional technical map, scale 1:10,000.

\begin{tabular}{lcc}
\hline Morphometric Parameters & Units & Value \\
\hline Basin area & $\mathrm{km}^{2}$ & 196.86 \\
Basin perimeter & $\mathrm{km}$ & 68.23 \\
Max elevation & $\mathrm{m}$ a.s.l. & 3,060 \\
Min elevation & $\mathrm{m}$ a.s.l. & 600 \\
Mean elevation & $\mathrm{m}$ a.s.l. & 1,871 \\
Basin circularity & & 0.53 \\
Drainage density & $\mathrm{km} / \mathrm{km}^{2}$ & 3.23 \\
Constant of channel maintenance & $\mathrm{km} / \mathrm{km}^{2}$ & 0.31 \\
Number of streams & $\mathrm{n}$ & 1,411 \\
Stream length & $\mathrm{km}$ & 635.42 \\
Bifurcation ratio (ponderale mean) & & 3.98 \\
Direct bifurcation ratio (ponderale mean) & & 3.00 \\
Bifurcation index (ponderale mean) & & 0.98 \\
Number of hierarchical anomalies & & 1,253 \\
Hierarchical anomaly density & & 6.36 \\
Hierarchical anomaly index & & 1.19 \\
\hline
\end{tabular}

a.s.l $=$ above sea level

to $18.0^{\circ} \mathrm{C}$ in August (mean annual $9.1^{\circ} \mathrm{C}$ ). The average annual days of frost is 92 [10]. An analysis of the rainfall events lasting some days was done over a span of ninety years $[9,11]$. The analysis points out that the most common rainfall event has a mean duration of 3 to 5 days, with the peak day occurring between days 2 and 4 . The seasonal distribution of rainfall events (for this basin, total rainfall $>100 \mathrm{~mm}$ ) has one maximum in autumn and another in the spring. Extreme rainfall events (for this basin, total rainfall $>250 \mathrm{~mm}$ ) last 8 days on average and most often peak on day 4 (39\%). These events occurred most often in spring and autumn.

\section{MATERIALS AND METHODS}

With this method, several thematic maps are constructed each representing a factor that conditions a landslide. The predisposing factors were chosen based on experience and knowledge of the region conditions, but an historical data landslides inventory has been added. In addition, the made widely use of GIS for analysis and map elaboration.

Landslide susceptibility is determined from the preparatory variables that make the slope susceptible to failure without actually initiating it. By combining these factors with the temporal aspect of triggering variables, a map according to the risk definition can be obtained. The primary objective is to generate susceptibility maps, the method was restricted to some conditioning factors. In this study, we used geology, geomorphology, land use, slope and aspect. These factors were derived partly from survey data and photointerpretation (second data entry, Fig. 2) and partly from a Digital Elevation Model (DEM Regione Piemonte, third data entry, Fig. 2). All the combining factors were inserted in the GIS as different layers. Each conditioning factor affects the landslide phenomena with a determinate weight [1]. Therefore, a weight was 
assigned to each combining factor basing our choice on exploring possible situations in alpine area (weight range $0-1$ in Table 2). Moreover, each factor includes different classes (e.g. the bedrock map is characterized by different lithologies). Each class has a different influence on landslide conditioning. We assigned a rating to each class, according to the influence that such a class has in this area. The ratings had values within a range from 1 to 10 and they are briefly specified in each class. The lower the rating is, the lower is the influence on landslide probability. Based on these ratings, through the use of GIS we converted the triggering factors from vector to raster and the GIS generated various maps, specific to each factor. We inserted these maps in a spatial analysis and we obtained a series of preliminary susceptibility maps using a simple raster calculation (addition and multiplication as in Fig. 3).

Then, we added to each map the raster of landslide historical inventory: the presence of landslide increases the landslide susceptibility, its absence doesn't affect susceptibility (feedback analysis). This process led to the generation of definitive landslide susceptibility maps.
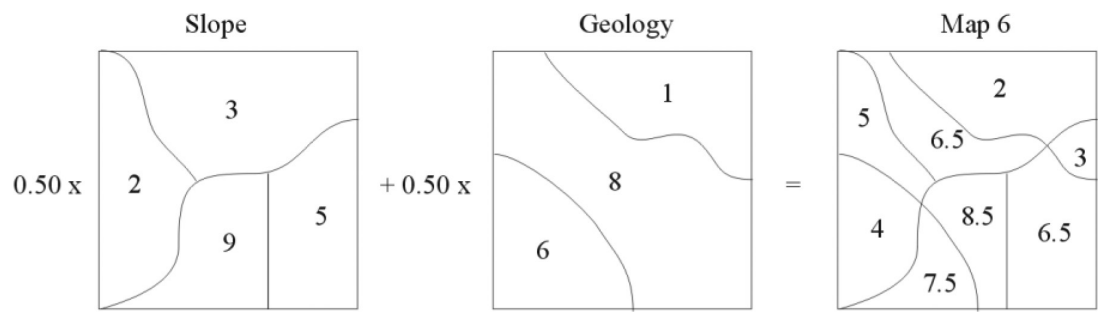

Figure 2: Flow chart of landslide susceptibility analysis.

Table 2: Causative factors and assigned weights for each susceptibility map.

\begin{tabular}{lcccccc}
\hline & Map 1 & Map 2 & Map 3 & Map 4 & Map 5 & Map 6 \\
\hline Aspect & 0.20 & 0.05 & 0.05 & 0.05 & 0 & 0 \\
Slope & 0.20 & 0.30 & 0.40 & 0.20 & 0.40 & 0.50 \\
Geology & 0.20 & 0.30 & 0.20 & 0.20 & 0.30 & 0.50 \\
Geomorphology & 0.20 & 0.30 & 0.30 & 0.40 & 0.30 & 0 \\
Land use & 0.20 & 0.05 & 0.05 & 0.05 & 0 & 0 \\
\hline
\end{tabular}
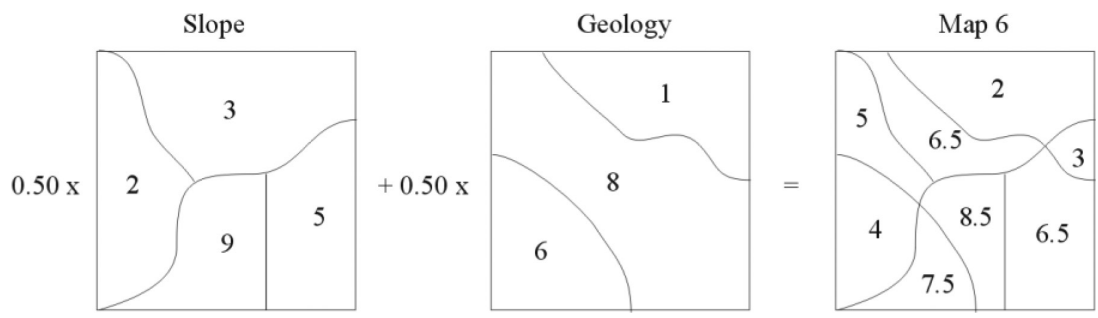

Figure 3: Sketch of the applied methodology for obtaining map 6; numbers and maps are only examples. The same sketch can be done for the other maps. 

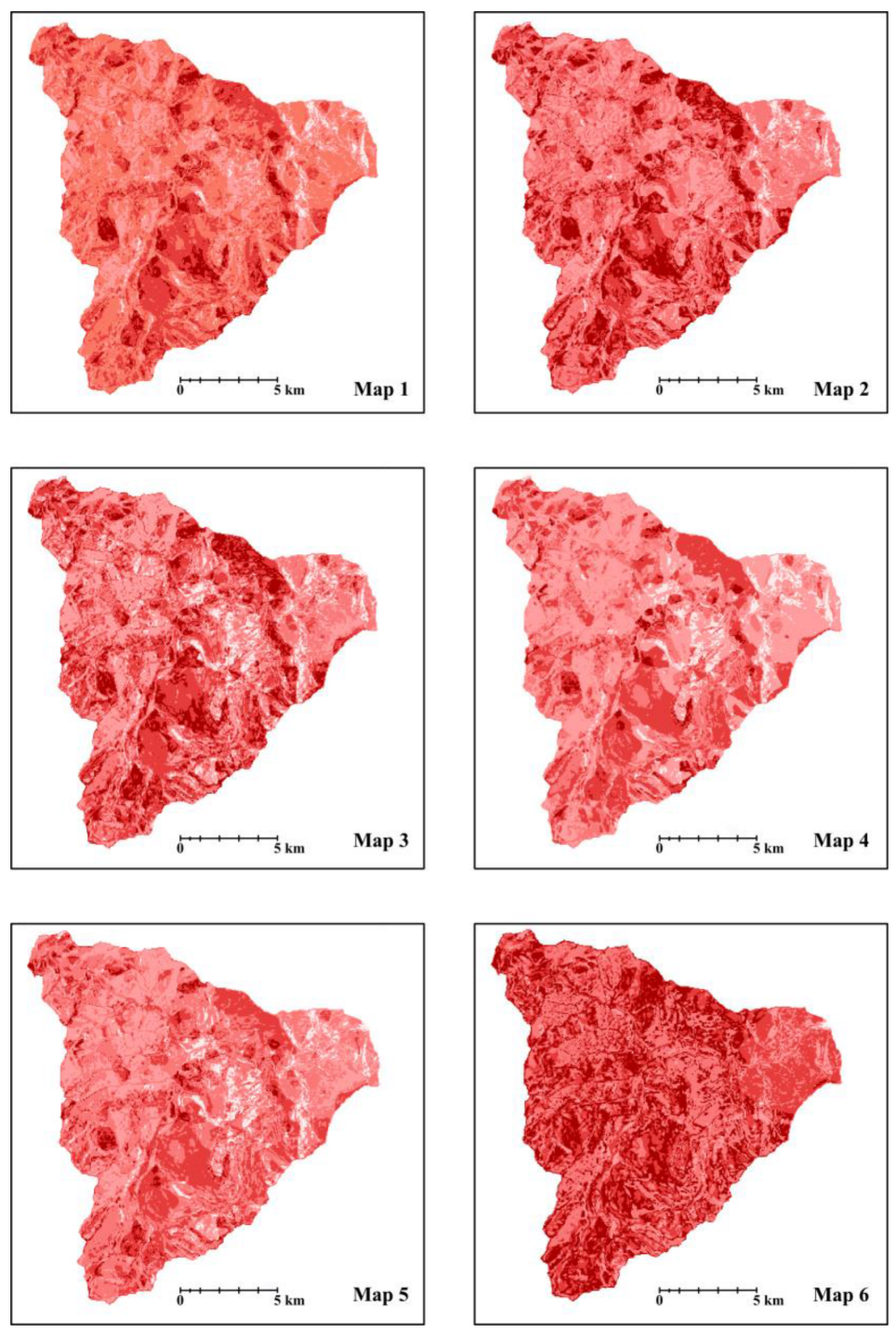

Figure 4: The classified susceptibility maps obtained with the method for the different combination of weight assignment. Intense red color denotes higher susceptibility.

These maps, however, cannot be directly used, but need to be reclassified, from high to low values, based on the frequency information from the histogram; processes directly made by the use of GIS (Fig. 4). Finally, a validation process for choosing the most reliable susceptibility map has to be done.

\subsection{Landslides inventory}

Landslide susceptibility evaluation should be based on a detailed analysis of land dynamics and previous landslides activities. The landslide inventory derived from the analysis of 
historical data and aerial photographs. The CNR-IRPI historical landslide inventory of the Germanasca Valley spans a period from 1,763 to the present. The inventory permits the retrieval of preliminary information about landslide location and timing. The historical inventory of the study area contains reports on 153 landslide events including rock falls, planar and rotational slides, complex landslides and debris flows. Moreover, the use of historical data for analyzing geomorphological processes implies a number of problems: absence of relevant evidence (magnitude, process duration and areal distribution) and historical data are not of first hand source. The correct approach implies a logical process that allows the extrapolation of useful information from the paper documents. This process has allowed to make the records more suitable for GIS. We inserted all the information in the GIS, using a specific tool, as a point layer because it is a better way to graphically represent standard historical data [12]. Since the historical research can leave some doubts about the distribution and the areal extension of each phenomenon, aerial photographic analysis can contribute importantly to complete the historical inventory and to have landslide distribution and reconstruction of their evolution in the last sixty years. The analysis was then compared with the published information from national studies [13]. For the purposes of our study, the landslide information taken from photointerpretation was digitized as polygons. This layer was then incorporated into the geomorphologic map of the basin.

\subsection{Geology}

The study area is located in the central part of the Western Alps where an imbricated stack of the continental crust (Dora Maira massif) and oceanic units (Piedmontese Zone) are recognizable [14]. In the upper basin of the valley there are outcrops of oceanic units (calcschists - high rating) with small but rather extensive metabasites and amphibolites (low rating). From the mid-valley to the confluence with the Chisone Stream the outcrops consist of lithotypes, such as graphitic micaschists (also with phengite, quartz, biotite and garnet), graphitic schists characterized by high foliation (low rating), fine-grained gneiss with a graphitic composition and metaconglomerates (medium to high rating [14]).

The quaternary deposits comprise glacial deposits in the summit areas of the valley, particularly evident talus at the foot of rocky outcroppings and deposits resulting from fluvial dynamics (medium to low rating).

\subsection{Geomorphology}

The Germanasca Valley is the product of fluvial and slope dynamics in glacial modeling. Traces of deposits and forms resulting from glacial modeling are now present only in the uppermost parts of the basin. The deposits and forms produced by fluvial and torrential dynamics are concentrated along rivers. Slope dynamics is the predominant modeling factor in the basin. Specifically, the characteristic geomorphologic context in which the area develops, slope steepness and its geology are among the chief reasons for the concentration of landslide phenomena in this area. About $30 \%$ of the study area is affected by the landslide. Based on aerial photographic analysis and fieldwork, the landslide inventory map, showed that most of the valley is characterized by extensive deep-seated gravitational deformations, partially reactivated as complex landslides, falls, small rock/debris slides and minor flows concentrated chiefly in stream incisions. The sectors in deep-seated gravitational deformations occupy about $30 \mathrm{~km}^{2}$ (15\% of the total area), while complex landslides about $12 \mathrm{~km}^{2}$ 
(6\% of the total area), such as falls and toppling. The last two are very common owing to the presence of various outcrops, particularly at higher elevations. Only about $1 \mathrm{~km}^{2}$ of this area is occupied by rock/debris slides similar for flow-prone areas and soil slips. Identifying flows was very difficult because the phenomena are punctual and not so common. Since the area occupied by flow and soil slip is so small, they were not considered in the susceptibility analysis. Ratings were assigned to stable and active landslides.

\subsection{Land use}

Vegetation cover and land use contribute less to defining landslide susceptibility than to implementing the preparatory variables listed above. Generally, barren areas are more subject to superficial erosion and wash out, whereas vegetation cover with a well developed root system may diminish processes affecting superficial soils (i.e. soil slip).

The type of vegetation and its degree of density will variously influence the rate of erosion in an area. Land-use analysis was conducted using a photointerpretation study of the basin [15]. The data were analyzed, grouped according to the vegetation class morphology. In this way, five classes were defined from low to high rating: streams, lakes and urban areas, agricultural land (pastureland and sown land), thickly vegetated areas (conifer and broad-leaved wood), sparsely vegetated areas (scrubland) and barren land.

\subsection{Slope angle}

The slope angle was obtained from a digital elevation model with a $50 \times 50 \mathrm{~m}$ grid and using Spatial Analyst GIS extension (DEM Regione Piemonte). Slope angle varies from $0^{\circ}$ at the valley bottom along the Germanasca Stream to over $60^{\circ}$ along the rocky banks of the upper valley; slope angle values were grouped into 10 classes of $5^{\circ}$. Ratings were assigned proportionally to the values and considering that the value for $0^{\circ}-5^{\circ}$ class is inherent only to the $5^{\circ}$ slope.

\subsection{Slope aspect}

Slope aspect was obtained from a digital elevation model with a $50 \times 50 \mathrm{~m}$ grid using Spatial Analyst GIS extension (DEM Regione Piemonte); slope aspect values were grouped into eight classes of $45^{\circ}$. The data show that the west-facing sectors (high rating) have the highest proportion of area susceptible to landslide comparing with inventory whereas those facing SE to NE (low rating) are characterized by the lowest percentage.

\section{RESULTS AND DISCUSSION}

The process enabled us to create various maps (Fig. 4) that differed in content regarding landslide susceptibility. Then, we validated the maps to identify the best correspondence to the real situation in the study area. The first step was a qualitative validation. All maps showed that the areas near the confluence of the Germanasca and Chisone rivers belong to the lowest landslide susceptibility class. Also the main drainage network is easy recognizable: a lower susceptibility class for the river and a higher class on the side slopes. Areas affected by pronounced glacial phenomena, generally characterized by undulated morphology and low slope angle, moderate amounts of debris and classified as pastureland, belonged to a low susceptibility class on all maps with the exception of map 6. Taken together, these observations provide a first evidence for the validity of the raster calculation. The quantitative validation 
was done by calculating the number of pixels for each susceptibility class and the number of pixels actually in a landslide area for each susceptibility class; then the percentage of landslides that really occurred in each susceptibility class was calculated. The work was done for each map. The percentage of surveyed landslides emphasizes the correspondence between the evaluated and the real susceptibility, particularly for the high susceptibility classes. Map 6 has a larger high and very high susceptibility area than the other maps. Considering the representativeness of the map, the percentage ratio between the number of pixels actually in a landslide area in high and very high susceptibility class and the number of pixels in the same class in the entire basin is the lowest (40\% instead of $80 \%-90 \%$ of the other maps). The map leads to overvalue of high susceptibility and to underestimate the lower one. The slope and geology are the main conditioning factors for landslides in the study area, but detailed geomorphological information can improve the spatial prediction. The weight assigned to the land use and the aspect does not affect the analysis substantially. Map 1 (with 0,20 weight for aspect and land-use) and map 5 (in which aspect and land use were not considered) shows a different distribution and area of susceptibility classes but almost the same percentage of surveyed landslides in each class, except for the very high value $(94 \%$ and $81 \%$, respectively). Aspect and land use are the factors that mainly conditioned shallow landslides, phenomena that are marginally present in this area, so they can be considered factors of lower importance. While, the aspect may be very important for falls, in these conditions, the elevation also has to be considered: the importance increases with altitude. All the other maps show almost the same percentage of all the susceptibility classes, map 2 presents the lowest value. This analysis is supported by the overlapping of the four different maps. The overlaying of map 2 with the others presents the lowest values. Overlaying the maps in twos, the best overlapping is represented by maps 3 and $5(54 \%)$. The main difference is the areas at very high and very low susceptibility, which are higher in the map 3. Map 4 (high geomorphological weight) best illustrates landslide area, but it has a rough susceptibility classification for the other parts of the basin. Map 2 has the highest percentage of medium susceptibility class but does not accurately represent the low susceptibility value. Maps 3 and 5 were generated with the same slope and geomorphology weight, but different geology, aspect and land use (Table 2). Comparing the two maps, using a Spatial Data analysis in the GIS, in the part of the basin where landslides are present, the susceptibility is the same for $38 \%$. Map 5 presents an underestimation of $58 \%$ and an overestimation of only $3 \%$. In the part of the basin where landslides are absent, the correspondence between susceptibility in the two maps is $61 \%$ and in the map 5 the underestimation is $26 \%$. In conclusion, the maps are both powerful, but map 3 is to be preferred, for a better conservative evaluation of susceptibility. So, in the study area, where the only slope and geology are combined the result is unacceptable. The use of aspect and land use changes the result slightly but the geomorphological information improves the susceptibility classification. A weight of 0.30 gives a reliable predictive power in the area not yet covered by landslides. One consideration concerns the geology of the areas classified as most susceptible to landslides. The high and very high classes comprised areas with geology composed of calcschists, phyllites and micaschists. Our results are in line with those from previous small-scale regional studies reporting landslide susceptible areas with geology consisting of much the same components [16].

\section{CONCLUSION}

Since the method was calibrated on this investigation site, it may be applied to territories where the lithological and morphological situations are similar; the alpine setting can be 
used. Furthermore, the final map can be easily analyzed also by non-specialized technicians and become a reliable tool for local authorities to individuate the risk area. Furthermore, such information could lay the basis for a more detailed study of landslide susceptibility in the area, for example, considering the different typology of landslides separately. In addition, landslide susceptibility of an unstable slope is closely correlated with diverse rock position and structure. Current ongoing studies will apply this method to map other basins in the Western Alps. The results of climate analysis studies examining rainfall characteristics, landslide and flooding [17] of the area will soon make it possible to evaluate the interaction between rainfall and landslide susceptibility. The landslide susceptibility map of the Germanasca Valley could provide a valuable reference for more accurate risk studies on site. While our study does not offer a complete solution to the problem, it may provide a useful tool for correct land-use planning and hazard management, which is of growing concern as human pressure on the environment increases. Moreover, in order to gain more insights into the risk evaluation, a subsequent step is the application of mathematical and numerical models that can be planned and focused to areas where the occurrence of landslides is most probable. The mathematical models are based on the balance of important physical quantities, closed with specific equations including the material behaviour, erosion [18], rheology. Numerical modeling is based on many different approaches, commonly very expensive by computer time point of view: Finite Element Method; Finite Difference Method and so on. However, more recently, a simplified, but reliable techniques, avoiding the cumbersome necessity to build a numerical grid, have been applied to study, in particular, fast landslides occurrence. Among these proposals the 'mesh-less' approach SPH (Smoothed Particle Hydrodynamics), seems to be very promising (among many others: [19-22]).

\section{ACKNOWLEDGEMENTS}

We wish to thank the Comunità Montana Valli Chisone e Germanasca (Piemonte, Italy) for providing some environmental shape files.

\section{REFERENCES}

[1] Cruden, D.M. \& Varnes, D.J., Landslides types and processes. In Landslides Investigation and Mitigation, Special Report 247, Transportation Research Board National Research Country, eds. A.K. Turner \& R.L. Schuster, National Academy Press: Washington, DC, pp. 36-75, 1996.

[2] Esposito, L., Esposito, A.W., Pasculli, A. \& Sciarra, N., Particular features of the physical and mechanical characteristics of certain Phlegraean pyroclastic soils. Catena, 104, pp. 186-194, 2013. http://dx.doi.org/10.1016/j.catena.2012.11.009

[3] Spieker, E.C. \& Gori, P.L., National landslide hazard mitigation strategy: a framework for loss reduction. USGS Open File Report 00-450, 49, 2000.

[4] Brabb, E.E., Innovative approaches to landslide hazard and risk mapping. Proceedings 4th ISL, Toronto Canada, pp. 307-324, 1984.

[5] Calista, M., Miccadei, E., Pasculli, A., Piacentini, T., Sciarra, M. \& Sciarra, N., Geomorphological features of the Montebello sul Sangro large landslide (Abruzzo, Central Italy). Journal of Maps, 12, pp. 1-10, 2015. http://dx.doi.org/10.1080/17445647.2015.1095134

[6] Clerici, A., Perego, S., Tellini, C. \& Vescovi, P., A procedure for landslide susceptibility zonation by the conditional analysis method. Geomorphology, 48, pp. 349-364, 2002. http://dx.doi.org/10.1016/S0169-555X(02)00079-X 
[7] Van Westen, C.J., Rengens, N. \& Soeters, R., Use of geomorphological information in indirect landslide susceptibility assessment. Natural Hazards, 30, pp. 399-419, 2003. http://dx.doi.org/10.1023/B:NHAZ.0000007097.42735.9e

[8] Yalcin, A. \& Bulut, F., Landslide susceptibility mapping using GIS and digital photogrammetric techniques: a case study from Ardesen (NE-Turkey). Natural Hazards, 41, pp. 201-226, 2007. http://dx.doi.org/10.1007/s11069-006-9030-0

[9] Nigrelli, G., Studio delle condizioni pluviometriche del bacino idrografico del Torrente Germanasca. GEAM, 111, pp. 49-56, 2004.

[10] Regione Piemonte, Distribuzione regionale di piogge e temperature. Collana studi climatologici in Piemonte, Vol 1, Direzione dei Servizi Tecnici di Prevenzione, Settore Meteoidrografico e Reti di Monitoraggio - Università degli Studi di Torino, Dipartimento di Scienze della Terra, 1998.

[11] Nigrelli, G., Analysis and characteristics of pluviometric events in the Germanasca Valley (Italian Western Alps). Geografia Fisica e Dinamica Quaternaria, 28, pp. 147-158, 2005.

[12] Audisio, C., Nigrelli, G. \& Lollino, G., A GIS tool for historical instability processes data entry: an approach to hazard management in two Italian Alpine river basins. Сomputers and Geosciences, 35(8), pp. 1735-1747, 2009; doi: 10.1016/j.cageo.2009.01.012. http://dx.doi.org/10.1016/j.cageo.2009.01.012

[13] ARPA Piemonte, Progetto IFFI: Web-site Visited on March 20 at http://www.arpa. piemonte.it, 2008.

[14] Borghi, A., Cadoppi, P., Porro, A., Sacchi, R. \& Sandrone, R., Osservazioni geologiche nella Val Germanasca e nella media Val Chisone (Alpi Cozie). Bollettino del Museo Regionale di Scienze Naturali, 2(2), pp. 504-529, 1984.

[15] Comunità Montana Valli Chisone e Germanasca, Piano di Bacino dei Torrenti Chisone e Germanasca, Unpublished report, p. 126, 2002.

[16] Regione Piemonte, Banca dati geologica. Settore prevenzione del rischio geologico, meteorologico e sismico Italian Government Report, 1990.

[17] Turconi, L., Nigrelli, G. \& Conte, R., Historical datum as a basis for a new GIS application to support civil protection services in NW Italy. Computers \& Geosciences, 66 , pp. 13-19, 2014; doi: 10.1016/j.cageo.2013.12.008.

http://dx.doi.org/10.1016/j.cageo.2013.12.008

[18] Pasculli, A. \& Sciarra, N., A Probabilistic approach to determine the local erosion of a watery debris flow. 11th International Congress for Mathematical Geology: Quantitative Geology from Multiple Sources, IAMG, Liege; Belgium, 2006; ISBN: 978-296006440-7; Scopus: 2-s2.0-84902449614.

[19] Minatti, L. \& Pasculli, A., Dam break smoothed particle hydrodynamic modeling based on Riemann solvers. 8th International Conference on Advances in Fluid Mechanics, AFM 2010; Algarve; Portugal, 69, pp. 145-156, 2010; ISBN; 9781845644765. http://dx.doi.org/10.2495/AFM100131

[20] Minatti, L. \& Pasculli, A., SPH numerical approach in modelling 2d muddy debris flow. 5th International Conference on Debris-Flow Hazards Mitigation Mechanics, Prediction and Assesment, pp. 467-475, 2011, ISBN: 9788895814469; doi: 10.4408/ IJEGE.2011-03.B-052.

[21] Pasculli, A., Minatti, L., Sciarra, N. \& Paris, E., SPH modeling of fast muddy debris flow: numerical and experimental comparison of certain commonly utilized approaches. 
Italian Journal of Geosciences, 132(3), pp. 350-365, 2013, doi: 10.3301/IJG.2013.01; Scopus: 2-s2.0-84886468697.

[22] Pasculli, A., Minatti, L., Audisio, C. \& Sciarra, N., Insights on the application of some current SPH approaches for the study of muddy debris flow: numerical and experimental comparison. 10th International Conference on Advances in Fluid Mechanics, AFM 2014, WIT Transactions on Engineering Sciences, 82, pp. 3-15, 2014; ISBN: 9781845647902; doi: 10.2495/AFM140011; Scopus: 2-s2.0-8490761123. 